\title{
Paternal preconceptional radiation exposure in the nuclear industry and leukaemia and non-Hodgkin's lymphoma in young people. in Scotland
}

\author{
LJ Kinlen, K Clarke, A Balkwill
}

\begin{abstract}
Objective-To determine if a relation exists between paternal exposure to relatively high levels of radiation in the Scottish nuclear industry and the risk of leukaemia and non-Hodgkin's lymphoma in subsequently conceived children.

Design-Matched case-control study with three controls for each case.

Setting-The whole of Scotland.

Subjects-The fathers of 1024 children with leukaemia and 237 children with non-Hodgkin's lymphoma diagnosed in Scotland below the age of 25 among those born in Scotland since nuclear operations began (in 1958) and the fathers of 3783 randomly chosen controls. The fathers of 80 children with leukaemia and 16 with non-Hodgkin's lymphoma in north Cumbria were also covered since some workers at one Scottish nuclear site live over the border in that area. Details of all fathers were then matched against records of the nuclear industry.

Main outcome measures-Paternal preconceptional radiation exposures, particularly relatively high levels, both lifetime and in the six and three months before conception.
\end{abstract}

Results-No significant excess was observed in any subgroup and there was no significant trend: fathers of three controls but no cases were exposed to lifetime preconceptional levels of $100 \mathrm{mSv}$ or greater (Fisher's exact $p$ value 0.84 ). In the six months before conception, fathers of two cases and three controls received $10 \mathrm{mSv}$ or more, odds ratio $2 \cdot 3(95 \%$ confidence interval $0 \cdot 31$ to $17 \cdot 24)$. In the three months before conception the fathers of one case and two controls received $5 \mathrm{mSv}$ or more, odds ratio $1.7(0.10$ to 30.76$)$. The results for leukaemia and non-Hodgkin's lymphoma combined were similar.

Conclusion-No significant excess of leukaemia or of leukaemia and non-Hodgkin's lymphoma was found at any radiation level in any preconceptional period.

Cancer Research

Campaign Epidemiology Unit, Department of Public Health and Primary Care, University of Oxford, Radcliffe Infirmary, Oxford OX2 6HE

L J Kinlen, director $\mathrm{K}$ Clarke, research associate A Balkwill, computer programmer

Correspondence to: Dr Kinlen.

$B M \mathcal{F} 1993 ; 306: 1153-8$

\section{Introduction}

An unexpected association has been reported recently between high paternal radiation doses in the nuclear industry (at Sellafield) before conception and subsequent leukaemia and non-Hodgkin's lymphoma in young people.' Any test of this hypothesis requires the identification, among the records of men employed in the nuclear industry, of the fathers of affected (and control) children. In practice this involves tracing the dates of birth of many fathers of these children many of whom died some years ago. In most of Britain this is far from straightforward, but in Scotland it is facilitated by the inclusion of additional details in birth and marriage registration records. We therefore investi- gated by a case-control study covering the whole of Scotland the possible relation between paternal preconceptional radiation in the Scottish nuclear industry and subsequent leukaemia and non-Hodgkin's lymphoma in young people.

\section{Methods}

CASES OF LEUKAEMIA AND NON-HODGKIN'S LYMPHOMA

Details were provided by the Scottish Cancer Registration Scheme of cases of leukaemia and nonHodgkin's lymphoma in the period 1958-90 among people aged under 25 who were born in or after 1958, the year in which nuclear operations began in Scotland. In addition, details of deaths from these causes were obtained from the registrar general and the names of the individuals concerned were then determined in Register House, Edinburgh. In this way, individuals who were not represented in the incomplete early years of the cancer registration scheme could be covered. These formed the principal study group, and in addition an attempt was made to cover two much smaller groups: children born in Scotland but whose disease was diagnosed outside, and cases in north Cumbria.

Complete ascertainment of cases of these malignancies diagnosed in England and Wales in the relevant calendar period and age group among individuals who were born in Scotland was not possible, but we included cases known from the nationwide datasets held by the Oxford Survey of Childhood Cancer and the Childhood Cancer Research Group. Some additional cases were found by searching records of deaths from childhood cancer in England and Wales which, since 1968, have indicated country of birth.

Inclusion of cases of leukaemia and non-Hodgkin's lymphoma among individuals who were born in or after 1958 in England in the Carlisle, Eden, and Allerdale districts of north Cumbria was prompted by the fact that part of the workforce of the Chapelcross nuclear power station lives over the Scottish border in north Cumbria. Cases in this area were ascertained through the Childhood Cancer Research Group, from death registrations, and through the Northern Young Persons' Malignant Disease Register.

\section{SELECTION OF CONTROLS}

Birth registration details were sought for the cases who were born in Scotland. For each birth certificate traced for a case child and which was associated with a paternal name, three control births of the same sex in the same county were chosen as follows. All the birth registers in the relevant county were examined (in a fixed order) to determine the numbers of births registered in the county and year in question (cities being treated as counties). In this way each birth in the county could be identified by a unique number. Three 
random numbers were then generated, not exceeding the total number of births in the county concerned, each leading to a specific birth entry which identified a potential control for a given case. (In north Cumbria, controls were chosen using random numbers from within the Carlisle and Penrith birth registers.) If the entry selected concerned a child of inappropriate sex or without a named father, the first suitable control was chosen from the following entries. Similarly, if a control was found to be already in the study as a case or as a control, that selection was replaced by another. As a result no child with leukaemia or non-Hodgkin's lymphoma diagnosed in Scotland could be selected as a control. At a later stage, an opportunity was provided for all control children to be checked against the Scottish NHS Central Register. This enabled any control child diagnosed with leukaemia or nonHodgkin's lymphoma since 1970 after moving to England or Wales to be identified (and excluded). This exercise also allowed control children who died before the age at diagnosis of their matched case to be identified; these were replaced by the next eligible entry in the birth register.

\section{TRACING PATERNAL DETAILS}

We attempted to trace the paternal dates of birth of all case and control children, utilising the fact that in Scotland (uniquely in Britain) the birth certificate includes a reference to details of marriage (if any). In this way, paternal age at marriage could be obtained from the registration details of the marriage (if this took place in Scotland), and in turn, the father's date of birth by tracing his birth registration details (if he had been born in Scotland). In Scotland, the marriage certificate shows the names of the parents (including the maiden name of the mother) of the marrying couple, just as the birth certificate does for the parents of the child. Acceptance of a birth certificate as relating to the man mentioned on a marriage certificate required the agreement not only of his name but also the names of both parents and of the maiden name of his mother.

The fathers of children aged 0-14 at diagnosis were investigated first and then matched against the records of nuclear workers (see below). The relevant children of almost all successfully matched men were born in, or adjacent to, counties containing nuclear sites. In view of this, and the laborious nature of the method (at most three cases and their controls could be dealt with per hour), paternal details of young people aged 15-24 at diagnosis, and of their controls, were sought only for those who were born in the "nuclear" counties of Caithness, Sutherland, Ayrshire, Dumfriesshire, Fife, Dumbartonshire, West Lothian, and Edinburgh.

\section{DETAILS OF NUCLEAR WORKERS}

Details of nuclear workers in Scotland were available from three sources.

(1) The four sections of the Scottish nuclear industry cooperated in the study by giving us access to details of all past and present male employees, hereafter referred to as nuclear workers. The industry comprises the Dounreay installation in Caithness (Atomic Energy Authority); the Hunterston and Torness power stations in Ayrshire and East Lothian respectively (Scottish Nuclear); the Chapelcross power station in Dumfriesshire (British Nuclear Fuels); and the Ministry of Defence, which includes naval and civilian employees at the Rosyth naval dockyard in Fife and the Faslane, Coleport, and Vulcan bases.

(2) The records of certain civilian workers in the Rosyth naval dockyard who receive only small radiation doses (less than $15 \mathrm{mSv}$ in a year, though in practice usually much less) are governed by special provisions under which their radiation records are not classified with the permanent records of other workers, and need not be retained for more than three years. In the event, however, it was possible to cover such records as far back as 1980 .

(3) In addition, the National Radiological Protection Board holds information about nuclear workers from the whole of the United Kingdom in the National Register of Radiation Workers. ${ }^{2}$ This will be used in a larger study of parental exposure to radiation and childhood cancer of which the present study will be a part. This register served as an independent check on the previous matching and also allowed some coverage of industrial radiographers and the employees of contractors working on nuclear sites since, except on Ministry of Defence sites, these are not represented in the records of the nuclear industry described above.

\section{MATCHING}

The above file of names and dates of fathers of cases and controls was matched against similar details of nuclear workers. We were provided with details of present and past employees at Hunterston, Torness, and Chapelcross. The Atomic Energy Authority and the Ministry of Defence, however, do not keep records of their Scottish employees separately. Partly for this reason, the matching exercise for employees at Dounreay and of the Ministry of Defence was carried out with our help in the central records section of those bodies. All matching was carried out in ignorance of the case or control status of each individual; paternal occupational details shown on birth or death certificates of the children; employment periods of the nuclear workers; the dates of birth of the relevant children; and the radiation exposures of the nuclear workers. Fathers whose date of birth was unknown were included in the matching exercise. Generous allowance was made for possible misspelling of surnames, incomplete forenames, and errors in parts of the birth dates. By this approach we aimed, besides identifying more obvious matches, to produce a series of possible matches which might then be the subject of detailed attention.

Possible matches were investigated, particularly through the national insurance section of the Department of Social Security, but also through the NHS Central Register and the Primary Health Boards. All available identifying details were used, including NHS number, addresses, and occupation of our study subjects, and national insurance number and addresses held by the nuclear industry. The aim was to obtain positive grounds not only for regarding a match as definite but also for rejecting all others; rejection usually meant determining that the records referred to separate identified individuals. Similar names were regarded as successfully matched if the dates of birth were identical, providing the address and occupation as given on the child's birth certificate were (at least) not inconsistent with the nuclear industry records. If the nuclear employment had ceased before the child's birth, a place of birth on the child's birth certificate distant from the nuclear site was allowed if the NHS Central Register indicated a previous address close to the nuclear site, consistent with the employment records. For fathers of unknown date of birth, a match was accepted if the precise address agreed in the two sets of records and national insurance records had excluded confusion with any other individual. Also accepted were fathers stated on their child's birth certificate to have an occupation compatible with those in the Ministry of Defence when their names and postings agreed with Ministry of Defence records.

The above procedure was followed in the case of all Scottish fathers, irrespective of the period of "nuclear" employment. However, because of the greater difficulty already described of tracing paternal dates of 
birth in England, possible matches involving north Cumbrian fathers were pursued only if the possible "nuclear" employment preceded the relevant birth. For the same reason, the fathers of cases diagnosed in north Cumbria were matched against nuclear industry records irrespective of the child's place of birth. Only when a match remained possible was the birth certificate of the child checked to determine whether he or she had been born in north Cumbria.

\section{CHECKS ON THE MATCHING PROCEDURE}

Details of paternal occupation on all birth and death certificates were carefully examined for any suggested employment at a nuclear power station, naval dockyard, or in the navy in case exposed individuals had been overlooked. Another check was provided by matching the file of study subjects against the National Register of Radiation Workers. ${ }^{2}$ This register does not claim to be complete-radiation workers who withheld their permission are not represented - and, in any case, any individual matched in this way who had been employed in the Scottish nuclear industry should have been identified by our previous matching exercise.

\section{RADIATION DETAILS}

For all men for whom a satisfactory match was made, radiation details were sought. These mainly referred to exposures in Scotland, though any such incurred during previous employment in the nuclear industry in England and Wales would also have been covered since details are routinely transferred to the new employer. Radiation details were obtained in the form of external total annual doses in millisieverts $(\mathrm{mSv})$ for each year from first employment up to the time of the study. Detailed monthly doses were then requested for three consecutive calendar years that included the six month period before conception of the relevant child, though this period was not specified in the request. Any records of neutron exposures were also obtained. Radiation doses were calculated for the critical periods proposed by Gardner et al-namely, the lifetime preconceptional exposure and the six months before conception. ${ }^{1}$ In addition, we calculated doses in the three months before conception, in which it is biologically plausible that any effect on germ cells would be greatest. The date of conception was taken to be 38 weeks ( 266 days) before the date of birth; six months was taken as 182 days and three months as 91 days.

\section{ANALYSIS}

Radiation exposures were analysed by using dose categories that included those of Gardner and his colleagues. $^{1}$ The results were calculated by using conditional logistic regression analysis with the computer program EGRET, ${ }^{3}$ which produces estimates of odds ratios approximating closely to relative risks, together with confidence intervals. When there were no cases in a particular category, Fisher's exact test was used on unmatched cases and controls to test a null hypothesis of homogeneity with the result shown

TABLE I-Leukaemia and non-Hodgkin's lymphoma in Scotland: number of cases by age group and calendar period of birth

\begin{tabular}{|c|c|c|c|c|c|c|c|c|}
\hline \multirow[b]{2}{*}{ Age (years) } & \multicolumn{4}{|c|}{ Leukaemia } & \multicolumn{4}{|c|}{ Non-Hodgkin's lymphoma } \\
\hline & $1958-70$ & $1971-80$ & $1981-90$ & Total & $1958-70$ & $1971-80$ & $1981-90$ & Total \\
\hline $0-4$ & 302 & 219 & 164 & 685 & 64 & 26 & 10 & 100 \\
\hline $5-14$ & 279 & 145 & 35 & 459 & 84 & 56 & 6 & 146 \\
\hline $15-24^{\star}$ & 47 & 6 & 0 & 53 & 31 & 4 & 0 & 35 \\
\hline Total & $628 t$ & 370 & 199 & 1197 & $179 \ddagger$ & 86 & 16 & 281 \\
\hline
\end{tabular}

*Nuclear counties only: Caithness, Sutherland, Ayrshire, Dumfriesshire, Fife, Dumbartonshire, West Lothian, Edinburgh.

+40 Cases identified only from death certificates.

$\$ 23$ Cases identified only from death certificates.
TABLE II-Scottish cases of leukaemia and non-Hodgkin's lymphoma and their controls: numbers by availability of birth and paternal details

\begin{tabular}{lccccc}
\hline & \multicolumn{3}{c}{ Cases } & & \\
\cline { 2 - 4 } & Leukaemia & $\begin{array}{c}\text { Non-Hodgkin's } \\
\text { lymphoma }\end{array}$ & Controls & Total \\
\hline $\begin{array}{l}\text { Diagnosed in Scotland } \\
\text { Birth certificate traced } \\
\text { in Scotland }\end{array}$ & 1197 & 281 & NA & 1478 \\
$\begin{array}{l}\text { Known paternal name } \\
\text { Paternal date of birth } \\
\text { traced }\end{array}$ & 1050 & 243 & NA & 1293 \\
NA=Not applicable. & 1024 & 237 & 3783 & 5044 \\
& 875 & 202 & 3220 & 4297 \\
\hline
\end{tabular}

as a $p$ value. Evidence of a dose-response effect (linear trend) was examined using a likelihood ratio test. ${ }^{4}$

\section{Results}

A total of 1197 Scottish cases of leukaemia and 281 of non-Hodgkin's lymphoma were investigated, all diagnosed below age 25 in individuals born after 1957 . Table I shows details of these 1478 cases by age group and calendar period of birth. In 1293 cases a Scottish birth certificate was traced so that (when 32 without a paternal name were excluded) the names of 1261 fathers were available, forming the principal subjects in this study (table II). Birth certificates could not be traced for the remaining 185; these would include name changes on account of adoption as well as births outside Scotland. For each of the 1261 (case) births associated with a paternal name, three control births were chosen at random from the births registered in the same year and county. When the controls were checked in the NHS Central Register no instance was found of leukaemia or non-Hodgkin's lymphoma in a control diagnosed after the person had moved to England or Wales, but this procedure resulted in replacement controls being chosen for 86 controls who died before the age at diagnosis of the relevant case. In this way, a total of 5044 names of fathers of cases and controls who were resident in Scotland at the birth of the children in question were assembled, 4297 with a date of birth. Added to these were 12 fathers of children with these malignancies who, though born in Scotland, had been diagnosed after moving to England and Wales, together with the fathers of 80 children with leukaemia and 16 with nonHodgkin's lymphoma from north Cumbria, and their controls: this gave a grand total of 5476 fathers who were investigated in the personnel records of the nuclear industry.

Among these 5476 men, 60 were matched definitely in the records of the Scottish nuclear industry and 12 in those for non-classified workers at Rosyth. Many of these 72 fathers were exposed to radiation only after the relevant conception, and only 38 had some preconceptional exposure. Only one match was obtained which involved a child born in north Cumbria. Another 23 possible additional matches were found in the National Register of Radiation Workers. None of these men belonged to the Scottish nuclear industry as defined above; all had been involved in industrial radiography. None therefore represented men who had been overlooked in the previous matching process. Again, most of the radiation exposure of these 23 men occurred after conception of the child, and only three definite matches were found involving preconceptional exposure. This gave a total of 41 case or control fathers who were found to have had some exposure to radiation before the conception of the relevant children (table III). Examination of paternal occupation as given on the birth certificate (together with associated checks) produced no instance of a match being overlooked. Each of the four sections of the Scottish nuclear industry was represented among the matched 
TABLE III-Details of fathers identified in records of Scottish nuclear industry and the National Register of Radiation Workers (NRRW)

\begin{tabular}{lccccc}
\hline & $\begin{array}{c}\text { No of } \\
\text { definite } \\
\text { matches }\end{array}$ & \multicolumn{3}{c}{$\begin{array}{c}\text { No with preconceptional } \\
\text { radiation exposure }\end{array}$} \\
\cline { 3 - 7 } & Cases & Controls & Total \\
\hline Nuclear industry (excluding non- & 60 & 11 & 27 & $38^{\star}$ \\
$\begin{array}{l}\text { classified records) } \\
\text { Rosyth (non-classified records) }\end{array}$ & 12 & 0 & 0 & 0 \\
NRRW but not included above & $(4-20) \dagger$ & 0 & 3 & 3 \\
\hline Total & $\geqslant 76$ & 11 & 30 & 41 \\
\hline *Including 1 from north Cumbria. & & & & \\
†Range given because attempt was made to establish definite matches \\
only for individuals with preconceptional radiation exposure.
\end{tabular}

fathers and also among both the cases and controls with radiation exposures before the relevant conception. Among the 60 fathers matched with nuclear industry records, the numbers who had worked at each nonMinistry of Defence site were approximately in proportion to the size of the total (ever employed) workforce: 25 at Dounreay, 12 at Hunterston, and seven at Chapelcross. (The numbers of men ever employed in Ministry of Defence nuclear work in Scotland is uncertain, many naval postings there being short term.) Fifty two of the above matched exactly on date of birth; of the other eight, for whom a date of birth had not been traced, five were described as servicemen on the child's birth certificate, their details matching with Ministry of Defence records of postings. In the three others, there was confirmation from the addresses and other particulars; in two, all three forenames matched.

Exposure details for the preconceptional period were traced for all but one of the fathers who were

TABLE IV-Relative risks for leukaemia in young people by external ionising radiation dose to father

\begin{tabular}{|c|c|c|c|c|c|}
\hline Father's exposure & $\begin{array}{c}\text { Cases } \\
(n=1115)\end{array}$ & $\begin{array}{l}\text { Controls } \\
(n=3345)\end{array}$ & $\begin{array}{c}\text { Odds ratio (95\% } \\
\text { Confidence interval) }\end{array}$ & $\begin{array}{l}\text { Likelihood ratio } \\
\text { test (df) }\end{array}$ & $\mathrm{p}$ Value \\
\hline \multicolumn{6}{|c|}{ Leukaemia } \\
\hline \multicolumn{6}{|l|}{ Before conception: } \\
\hline 0 & 1104 & 3318 & 1.00 & & \\
\hline \multirow[t]{2}{*}{ Any } & 11 & 27 & $1.26(0.59$ to 3.90$)$ & $0.35(1)$ & $p=0.55$ \\
\hline & & By dose & & & \\
\hline \multicolumn{6}{|l|}{ Before conception: } \\
\hline 0 & 1104 & 3318 & 1.00 & & \\
\hline $0.01-49.99 \mathrm{mSv}$ & 9 & 21 & $1.32(0.58$ to 3.02$)$ & & \\
\hline$\geqslant 50 \mathrm{mSv}$ & 2 & 6 & $1.04(0.21$ to 5.17$)$ & $0.43(2)$ & $\mathrm{p}=0.81$ \\
\hline \multicolumn{6}{|c|}{ In 6 months before conception: } \\
\hline 0 & 1107 & 3328 & 1.00 & & \\
\hline $0.01-4.99 \mathrm{mSv}$ & 6 & 12 & $1.64(0.55$ to 4.89$)$ & & \\
\hline$\geqslant 5 \mathrm{mSv}$ & 2 & 5 & $1.26(0.22 \text { to } 7 \cdot 19)^{\star}$ & $0.81(2)$ & $p=0.67$ \\
\hline \multicolumn{6}{|c|}{ In 3 months before conception: } \\
\hline 0 & 1107 & 3329 & $1 \cdot 00$ & & \\
\hline $0.01-2.49 \mathrm{mSv}$ & 6 & 11 & $1.84(0.66$ to 5.70$)$ & & \\
\hline$\geqslant 2.5 \mathrm{mSv}$ & 2 & 5 & $1.27(0.22$ to 7.26$) t$ & $1 \cdot 15(2)$ & $p=0.56$ \\
\hline
\end{tabular}

*Includes father of a control with dose of $5.05 \mathrm{mSv}$, of which $3.17 \mathrm{mSv}$ was notional.

tIncludes father of a control with dose of $3.92 \mathrm{mSv}$, of which $3.17 \mathrm{mSv}$ was notional.

TABLE $\mathrm{V}-$ Relative risks for leukaemia and non-Hodgkin's lymphoma in young people by external ionising radiation dose to father

\begin{tabular}{lccccc}
\hline & $\begin{array}{c}\text { Cases } \\
(n=1369)\end{array}$ & $\begin{array}{c}\text { Controls } \\
(n=4107)\end{array}$ & $\begin{array}{c}\text { Odds ratio }(95 \% \\
\text { Confidence interval })\end{array}$ & $\begin{array}{c}\text { Likelihood ratio } \\
\text { test }(\mathrm{df})\end{array}$ & $\mathrm{p}$ Value \\
\hline
\end{tabular}

\begin{tabular}{|c|c|c|c|c|c|}
\hline \multicolumn{6}{|c|}{ Leukaemia and non-Hodgkin's lymphoma } \\
\hline \multicolumn{6}{|l|}{ Before conception: } \\
\hline 0 & 1358 & 4077 & $1 \cdot 00$ & & \\
\hline \multirow[t]{2}{*}{ Any } & 11 & 30 & $1.11(0.53$ to 2.33$)$ & $0.08(1)$ & $p=0.78$ \\
\hline & \multicolumn{3}{|c|}{ By dose } & & \\
\hline \multicolumn{6}{|l|}{ Before conception: } \\
\hline 0 & 1358 & 4077 & 1.00 & & \\
\hline $0.01-49.99 \mathrm{mSv}$ & 9 & 24 & $1.14(0.51$ to 2.54$)$ & & \\
\hline$\geqslant 50 \mathrm{mSv}$ & 2 & 6 & $1.02(0.20$ to 5.06$)$ & $0 \cdot 10(2)$ & $p=0.95$ \\
\hline \multicolumn{6}{|c|}{ In 6 months before conception: ${ }^{\star}$} \\
\hline 0 & 1361 & 4087 & 1.00 & & \\
\hline $0.01-4.99 \mathrm{mSv}$ & 6 & 14 & $1.35(0.47$ to 3.82$)$ & & \\
\hline$\geqslant 5 \mathrm{mSv}$ & 2 & 5 & $1.25(0.22$ to 7.08$) \dagger$ & $0.36(2)$ & $p=0.84$ \\
\hline \multicolumn{6}{|c|}{ In 3 months before conception: ${ }^{\star}$} \\
\hline 0 & 1361 & 4089 & $1 \cdot 00$ & & \\
\hline $0.01-2.49 \mathrm{mSv}$ & 6 & 12 & $1.64(0.55$ to 4.89$)$ & & \\
\hline$\geqslant 2.5 \mathrm{mSv}$ & 2 & 5 & $1.26(0.22$ to $7 \cdot 19) \ddagger$ & $0.81(2)$ & $p=0.67$ \\
\hline
\end{tabular}

* One father of above 4107 controls excluded (dosage details not available by calendar period).

†Includes father of a control with dose of $5.05 \mathrm{mSv}$, of which $3.17 \mathrm{mSv}$ was notional.

‡Includes father of a control with dose of $3.92 \mathrm{mSv}$, of which $3.17 \mathrm{mSv}$ was notional. successfully matched with the occupational records. The exception, the father of a control for nonHodgkin's lymphoma, was found in the National Register of Radiation Workers and had worked in industrial radiography outside the Scottish Nuclear Industry from 1956 until 1986, accumulating a lifetime dose of $233 \mathrm{mSv}$. However, no dosage details were available by calendar period and, in particular, not for the period before the relevant conception (in 1959). He was included in the lowest lifetime exposure category (above zero but less than $50 \mathrm{mSv}$ ) but he was excluded from all analyses relating to the three and six month periods before conception. In addition, the father of one of the leukaemia controls warrants mention since the occupation on his child's birth certificate indicated employment in American nuclear powered submarines. However, the US Navy has informed us that no record of occupational exposure to radiation could be traced for this subject.

Table IV shows estimates of relative risk of leukaemia associated with any radiation exposure (that is, $>0.0 \mathrm{mSv}$ ) before conception. Also shown are the corresponding values by level of paternal radiation exposure in three periods before conception-namely, lifetime and in the six month and three month periods. No significantly increased risk was associated with any preconceptional radiation exposure, nor with any level in any of the three periods considered. There was no significant dose-reponse gradient. Part of the dose in the three month period before conception in the record of the father of one control was notional. If this dose were omitted, the trend test for leukaemia would be affected only slightly $(p=0.60$; for the six month period, $p=0.69$ ). The corresponding data for leukaemia plus non-Hodgkin's lymphoma are presented in table V; again, no dose response effect or significant excess was found at any level of paternal exposure to radiation.

Details for the preconception dose levels at which significant excesses of leukaemia have been reported are given in table VI, namely for lifetime doses of 100 $\mathrm{mSv}$ or more and doses of $10 \mathrm{mSv}$ or more in the six months before conception. These could not be included in tables IV and V because in those matched analyses the lack of cases in certain cells precluded estimation of the odds ratios. The odds ratio for the lifetime high level risk $(0 \cdot 00$, Fisher's exact $\mathrm{p}$ value $0.84)$ and for the six month high level risk $(2 \cdot 30 ; 95 \%$ confidence limits 0.31 to 17.24 ) did not significantly deviate from unity. Also shown are the results of a matched analysis of four exposure levels for the three month period before conception: for levels of $5 \mathrm{mSv}$ or more the odds ratio for leukaemia was $1.73(0.10$ to 30.76).

Few subjects in the study were recorded as having any neutron exposures before the relevant child was conceived: $0.4 \mathrm{mSv}$ in each of two cases and $6.4,9.3$, $0 \cdot 8,8 \cdot 2$, and $0 \cdot 1 \mathrm{mSv}$ in each of five controls. One of these men, the father of a leukaemia control, received $4.94 \mathrm{mSv}$ in the three months before the child was conceived, of which $1.0 \mathrm{mSv}$ was from neutrons. No other case or control with neutron exposure was near the upper limit of any dose category in any period. If, as has been proposed, ${ }^{6}$ a higher quality factor (than the current 10) for neutron exposure had been used, the effective dose in this subject would have risen from 4.94 to over $5 \mathrm{mSv}$ in this three month period, causing the odds ratio shown in table VI for this dose level to fall from 1.73 to 1.07 ( $95 \%$ confidence limits 0.09 to 13.14) and for leukaemia and non-Hodgkin's lymphoma to $1.06(0.09$ to $12 \cdot 87)$.

\section{Discussion}

This study of leukaemia and non-Hodgkin's 
TABLE VI-Number of cases and controls and odds ratio or Fisher's exact $p$ value for the highest categories of father's external radiation exposure ( $m S v)$ before conception of child

\begin{tabular}{|c|c|c|c|c|c|}
\hline Father's exposure & $\begin{array}{l}\text { No of } \\
\text { cases }\end{array}$ & $\begin{array}{l}\text { No of } \\
\text { controls }\end{array}$ & $\begin{array}{l}\text { Odds ratio (95\% } \\
\text { Confidence interval) }\end{array}$ & $\begin{array}{l}\text { Likelihood ratio } \\
\text { test (df) }\end{array}$ & $\mathrm{p}$ Value \\
\hline \multicolumn{6}{|c|}{ Leukaemia } \\
\hline \multicolumn{6}{|c|}{ Lifetime up to conception: } \\
\hline $\begin{array}{l}<100 \mathrm{mSv} \\
\geqslant 100 \mathrm{mSv}\end{array}$ & $\begin{array}{r}1115 \\
0\end{array}$ & $\begin{array}{r}3342 \\
3\end{array}$ & 0.00 & & $\mathrm{p}=0 \cdot 84^{\star}$ \\
\hline \multicolumn{6}{|c|}{ In 6 months before conception: } \\
\hline$<10 \mathrm{mSv}$ & 1113 & 3342 & $1 \cdot 00$ & & \\
\hline$\geqslant 10 \mathrm{mSv}$ & 2 & 3 & $2.30(0.31$ to 17.24$) \dagger$ & & \\
\hline \multicolumn{6}{|c|}{ In 3 months before conception: } \\
\hline$<5 \mathrm{mSv}$ & 1114 & 3343 & 1.00 & & \\
\hline$\geqslant 5 \mathrm{mSv}$ & 1 & 2 & $1.73(0.10$ to 30.76$) \dagger$ & & \\
\hline 0 & 1107 & 3329 & 1.00 & & \\
\hline $0.01-2.49 \mathrm{mSv}$ & 6 & 11 & $1.84(0.59$ to 5.67$)$ & & \\
\hline $2.50-4.99 \mathrm{mSv}$ & 1 & 3 & $1.06(0.11$ to 10.25$) \ddagger$ & & \\
\hline$\geqslant 5 \mathrm{mSv}$ & 1 & 2 & $1.73(0.10$ to 30.76$)$ & $1 \cdot 22(3)$ & $\mathrm{p}=0.75$ \\
\hline \multicolumn{6}{|c|}{ Leukaemia and non-Hodgkin's lymphoma } \\
\hline \multicolumn{6}{|c|}{ In 3 months before conception: } \\
\hline 0 & 1361 & 4089 & 1.00 & & \\
\hline $0.01-2.49 \mathrm{mSv}$ & 6 & 12 & $1.47(0.51$ to 4.27$)$ & & \\
\hline $2.50 .4 .99 \mathrm{mSv}$ & 1 & 3 & $1.04(0.11$ to 10.00$) \ddagger$ & & \\
\hline$\geqslant 5 \mathrm{mSv}$ & $i$ & 2 & $1.73(0 \cdot 10$ to $30 \cdot 76)$ & $0.63(3)$ & $p=0.89$ \\
\hline
\end{tabular}

*Fisher's exact $p$ value

fOdds ratios and confidence limits for leukaemia and non-Hodgkin's lymphoma are the same.

$\ddagger$ Includes father of a control with a dose of $3.92 \mathrm{mSv}$, of which $3 \cdot 17$ was notional.

lymphoma, like the recent Canadian study of leukaemia, ${ }^{7}$ found no significant association with paternal preconceptional exposure to radiation as reported by Gardner and colleagues.' The latter study, covering the area near Sellafield, found an odds ratio (using parish controls) of 8.30 ( $95 \%$ confidence interval 1.36 to 50.56 ) for these malignancies in the children of men with a lifetime dose (up to the time the child was conceived) of $100 \mathrm{mSv}$ or greater. We found three men in this category, all fathers of controls (odds ratio 0.00 ), an unlikely finding if the true odds were 8.3 $(0.028$ is the conditional probability under this assumption) let alone the higher values of the confidence interval (up to $50 \cdot 5$ ). Our findings would also make unlikely a true odds ratio of $5 \cdot 2$, at the upper $95 \%$ confidence limit of our odds ratio. However, if all available evidence were to be used and our data were combined with that from the Canadian study (which found five controls but no cases in this category), ${ }^{7}$ an appreciably lower level of risk could be excluded. Gardner et al reported an odds ratio of $5 \cdot 0^{1}$ (later corrected to $4 \cdot 5^{5} ; 1.08$ to $18 \cdot 78$ ) for leukaemia and nonHodgkin's lymphoma in relation to exposures of 10 $\mathrm{mSv}$ or more in the six months before conception. (The period specified suggests greater precision than was available since the figures were based on a halving of the estimated dose in the year before conception.) In our study an odds ratio of $2.30(0.31$ to 17.24$)$ was found for this dose level as actually recorded in the six months before conception (table VI).

If paternal radiation had an effect in the six months before conception, as postulated, it is biologically plausible that this effect would be greatest in the three months before conception. For this period our odds ratio for $5 \mathrm{mSv}$ or more was $1.73(0 \cdot 10$ to $30 \cdot 76)$, based on one case and two controls. The wide confidence interval of our odds ratio for the six month preconceptional period make it consistent with that in the original study, ${ }^{1}$ although there the halving of the estimated dose in the 12 month period introduces a level of uncertainty. The number of workers exposed to relatively high levels in our study was small. Indeed, the potential effects on the odds ratio of minor changes is indicated by its decline from 1.73 for the high exposure level in the three months before conception to 1.06 if, as has been proposed, ${ }^{6}$ a higher quality factor for neutron exposure than the current 10 had been used.

The proportion of fathers of controls exposed to radiation before the child was conceived was much smaller $(0.8 \%)$ in our study than in the original study
$(15.9 \%)$ or in the recent Canadian study $(6.0 \%)$. This is to be expected as the latter studies were conducted in the vicinity of nuclear facilities whereas we covered the whole of Scotland. However, the concordant sets, all unexposed subjects, make no contribution to the results of these matched analyses, and the differences are less with respect to the absolute numbers of exposed fathers of cases and controls. Exposed fathers of leukaemia cases and controls, respectively, number 11 and 27 in this study, 9 and 45 in the original, ${ }^{1}$ and 6 and 53 in the Canadian study. ${ }^{7}$ The first two of these studies primarily concerned nuclear plant workers whose radiation exposure was monitored by monthly badge readings. The Canadian study included uranium miners whose radiation exposure (mainly due to radon) was until recently monitored differently, so that their external whole body exposures had to be inferred. If only exposed non-miners in that study are considered, the numbers are two cases and 31 controls.

A larger study of this subject covering England and Wales has been started using the databases of the Childhood Cancer Research Group, the Oxford Survey of Childhood Cancer, and the National Register of Radiation Workers. ${ }^{8}$ Our use of the national register to check our main findings provides an indication of its completeness and effectiveness for the larger study. Of the 60 fathers whom we successfully identified in the records of the nuclear industry, 47 were also found in the register, and of the remaining 13,11 had no radiation exposure before the conception of the relevant child. This augurs well for the newly launched study; its value is underlined by the importance of the subject and the relatively small numbers of exposed workers in the present study.

Our study fails to confirm the hypothesis that high doses of paternal preconceptional radiation can significantly increase the subsequent risk of childhood leukaemia. The study's statistical power is limited and the findings cannot exclude some relation, though they make it unlikely that the eightfold risk reported to be associated with high lifetime levels is correct. A striking aspect of this association found in the study in west Cumbria is its concentration in Seascale, ${ }^{1}$ though most men who work at Sellafield live outside this parish. Suggested alternative explanations for the excess of leukaemia and non-Hodgkin's lymphoma in Seascale include an unidentified chemical leukaemogen $^{10}$ and an (infective) epidemic promoted by the unusual population mixing in an isolated area of high social class, " though support from other studies exists only for the latter hypothesis. ${ }^{11-15}$ But if the present study and the Canadian work fail to confirm the claimed relation with paternal preconceptional radiation they equally raise questions about the nature of the unexpected association in the original study. ${ }^{1}$ This might reflect the throw of chance or an indirect relation between paternal radiation exposures and the true cause.

Even if paternal radiation were a genuine cause of childhood leukaemia it could not explain the Seascale excess. Of the 11 cases of leukaemia and nonHodgkin's lymphoma in Seascale the fathers of only two have so far been reported to be associated with the lifetime external levels ( $100 \mathrm{mSv}$ or more) before conception of the relevant child that Gardner and his colleagues linked to an excess of childhood leukaemia (a third case had been included inappropriately among the Seascale $\operatorname{cases}^{16}$ ). An additional two cases would qualify for inclusion if the high level category were redefined after inspection of the data as $>90 \mathrm{mSv}$. Attention has been drawn to the lack of information about any paternal radiation on three Seascale cases outside the original case-control study, ${ }^{17}$ and this also applies to the two subsequently recorded cases. ${ }^{16}$ It has recently been shown that four of these five cases were, 
like one of the cases in the case-control study, ${ }^{1}$ not associated with appreciable paternal radiation before conception. $^{18}$ The hypothesis therefore originated largely in a subgroup of the cases that aroused the concern which led to the study. It is well known that hypotheses based on subgroups are often unreliable.

The findings provide little support for a relation between paternal preconceptional radiation and subsequent leukaemia and non-Hodgkin's lymphoma in the offspring. Indeed, if considered with the findings of studies of radiation workers in $\mathrm{Canada}^{7}$ and of atomic bomb survivors ${ }^{9}$ they weigh against such a relation.

We are grateful to the Committee on Medical Aspects of Radiation in the Environment (COMARE) and the Health and Safety Policy Exchange Meeting of the UK Nuclear Operators for facilitating this study. We also thank the Scottish Cancer Registration Scheme and Jan Warner for providing cancer registration details; the Northern Young Persons' Malignant Disease Register (Professor Alan Craft); the Childhood Cancer Research Group (Charles Stiller); and the Office of Population Censuses and Surveys for corresponding details for north Cumbria; Dr Louise Parker for choosing control births in north Cumbria; the Atomic Energy Authority (and particularly Len Salmon and Dallas Law), British Nuclear Fuels (Dr Roger Berry, Keith Binks, W Davies, Sheila Roe), the Defence Radiological Protection Service (Surgeon Captain John Harrison, Philip Sinkinson, Graham Hughes), and Scottish Nuclear (Dr Graham Stewart, Dr J McKeown, Dr Christopher Kalman) and the health physics department of the Rosyth Royal Dockyard (Julie Tooley) for providing workforce and radiation details; the National Radiological Protection Board (Dr G M Kendall, Mark Webb), Jean Luthwaite, and the Department of Social Security for help with certain doubtful matches; the NHS Central Register for Scotland (William McMaster); Francesca Michalak, Marjorie Macleod, Vicky Stephenson, and Maureen Lumsden for their work in Register House in Edinburgh; Dr Gillian Mann for details of certain diagnoses revised by COMARE; Helena Strange, Susan Hill, and Janette Wallis for clerical help; Mark Dickson and Richard Hickling for computing assistance; Fiona Smith and Sally Price for secretarial help; and Dr Valerie Beral, Dr Paula
Cook-Mozaffari, Sir Richard Doll, and Professor P G Smith for their comments.

1 Gardner MJ, Snee MP, Hall AJ, Downes S, Powell CA, Downes S, Terrell JD. Results of case-control study of leukaemia and lymphoma among young people near Sellafield nuclear plant in west Cumbria. BMF 1990;300:423-9.

2 Kendall GM, O'Hagan JA, Rees S, Walker SM, Muirhead CR. Summary of the data held by the National Registry for Radiation Workers. London: HMSO, 1988. (NRPB-R219.)

3 Statistics and Epidemiology Research Corporation. EGRET. Seattle: SERC, 1991.

4 Breslow NE, Day NE. Statistical methods in cancer research. Vol I. The analysis of case-control studies. Lyons: International Agency for Research on Cancer, 1980

5 Gardner MJ. Paternal occupations of children with leukaemia. BMJ 1992;305: 715.

6 International Commission on Radiological Protection. 1990 Recommendation of the International Commission on Radiological Protection. Oxford: Pergamon Press, 1991. (ICRP 60.)

7 McLaughlin JR, Anderson TW, Clarke EA, King W. Occupational exposure of fathers to ionizing radiation and the risk of leukaemia in offspring-a case-control study. Ottawa: Atomic Energy Control Board, 1992. (Research Report INFO-0424.)

8 Draper GJ, Kendall GM, Muirhead CR, Sarahan T, Fox AJ, Kinlen LJ. Cancer in the children of radiation workers. Radiological Protection Bulletin 1992;129:10-4.

9 Yoshimoto Y, Neel JV, Schull WJ, Kato H, Soda M, Eto R, et al. Malignan tumors during the first two decades of life in the offspring of atomic bomb tumors during the first two decades of life in th

10 Evans HJ. Leukaemia and radiation. Nature 1990;345:16-7.

11 Kinlen L. Evidence for an infective cause of childhood leukaemia: comparison of a Scottish new town with nuclear reprocessing sites in Britain. Lance 1988;ii:1323-7.

12 Kinlen LJ, Clarke K, Hudson C. Evidence from population mixing in British new towns 1946-85 of an infective basis for childhood leukaemia. Lance 1990;336:577-82

13 Kinlen LJ, Hudson C, Stiller C. Contacts between adults as evidence for an infective origin of childhood leukaemia: an explanation for the excess nea nuclear establishments in West Berkshire? Br f Cancer 1991;64:549-54.

14 Kinlen LJ, Hudson C. Childhood leukaemia and poliomyelitis in relation to military encampments in England and Wales in the period of nationa military service 1950-63. BMF 1991;303:1357-62.

15 Kinlen LJ, O'Brien F, Clarke K, Balkwill A, Matthews F. Rural population mixing and childhood leukaemia: effects of the North Sea oil industry in mixing and childhood leukaemia: effects of the North Sea oil industry in 306:743-8.

16 Draper GJ, Stiller CA, Cartwright RA, Craft AW, Vincent TJ. Cancer in Cumbria and in the vicinity of the Sellafield nuclear installation, 1963-90. $B M f$ 1993;306:89-94.

17 Kinlen LJ. Leukaemia and lymphoma among young people near Sellafield. $B M{ }^{\prime} 1990 ; 300: 677$.

18 Kinlen LJ. Can paternal preconceptual radiation account for the increase of leukaemia and non-Hodgkin's lymphoma in Seascale? BMY 1993 (in press).

(Accepted 29 March 1993)

\section{Effects of computer generated reminder charts on patients' compliance with drug regimens}

Department of Pharmacy, Seacroft and Killingbeck Hospitals, Leeds LS14 6UH

D K Raynor, director of pharmacy and sterile services

Pharmacy Practice Research Unit, University of Bradford, Bradford BD7 1DP

T G Booth, professor of pharmacy practice

Centre for Pharmacy Postgraduate Education, University of Manchester, Manchester M60 7LP

A Blenkinsopp, director

Correspondence to:

Dr Raynor.

BMF 1993;306:1158-61

\section{K Raynor, T G Booth, A Blenkinsopp}

\section{Abstract}

Objective-To investigate whether a reminder chart improved patients' compliance with their drug regimen after discharge from hospital.

Design-Patients were randomly allocated to one of four groups. Two groups received the reminder chart: one also received routine counselling from a nurse and the other received structured counselling from a pharmacist, which included an explanation of the reminder chart. The other two groups received only counselling, either from a nurse or from a pharmacist. Patients were visited about 10 days later: they were questioned about their drug regimen, and their compliance was measured by tablet counting.

Setting-The pharmacy in a district general hospital and patients' homes.

Patients-197 patients being discharged from hospital who were regularly taking two or more drugs.

Intervention-An individualised reminder chart, which listed each person's medicines and when they were to be taken and was automatically generated by a medicine labelling computer.
Main outcome measures-Patient's compliance with and knowledge of their drug regimen.

Main results-Of the patients who received the reminder chart, $83 \%$ (95\% confidence interval $74 \%$ to $90 \%$ ) correctly described their dose regimen compared with $47 \%(37 \%$ to $58 \%)$ of those without the chart $(\mathbf{p}<0.001)$. The mean compliance score was $86 \%(81 \%$ to $91 \%)$ in both groups not given the reminder chart; $91 \%(87 \%$ to $94 \%)$ in the group given the chart without an explanation; and $95 \%$ (93\% to $98 \%$ ) in the group given the chart and an explanation. A mean compliance score of $>\mathbf{8 5} \%$ was achieved by $63 \%(53 \%$ to $73 \%)$ of patients without a reminder chart and by $86 \%(78 \%$ to $93 \%)$ of those receiving the chart $(\mathbf{p}<0 \cdot 001)$.

Conclusions-An automatically generated reminder chart is a practical and cost effective aid to compliance.

\section{Introduction}

Patients often have poor knowledge of their prescribed drug regimen and so do not comply fully with it. ${ }^{12}$ Well designed reminder charts can help with 